\title{
Transmedia as a Bridge to Favor Media Literacy in Formal Education
}

\author{
Patricia Gallo, Maria das Graças Pinto Coelho \\ Federal University of Rio Grande do Norte
}

\begin{abstract}
This paper aims to contribute to the debate on media literacy in formal education, calling attention to student learning when some skills are linked with technologies' and media's potentials. Accordingly, with a collaborative research methodology for investigating teaching and learning, our proposal is to encourage Transmedia as a complementary and participatory activity in the students' learning process, both when they are inside and outside of school, creating a bridge between media interaction and cognition. Transmedia not only provides a multimodality experience, seeking and following stories and information but also can open up opportunities in the learning process, such as problem-solving, creating common goals, remixing media content, checking information credibility, spreading content, negotiating and respecting points of view, and others. We cannot ignore the fact that children and youth are growing up using technology and media platforms in their daily lives. We focus our public target on youth aged 16 to 20 who are students in high school or in the first years of college, specifically to take advantage of the communication potential that they can have using technologies and media platforms for their own learning at school/colleges, rather than pushing it away.
\end{abstract}

\section{Introduction}

To interact with the world using many technologies and medias platforms requires specific skills and competencies (expertise) to participate in a culture that seeks, selects, creates, manipulates (manages) and organizes information. The appearance or adaptation of some cultural practices makes it more evident that the ownership of new signs and languages, new technological tools, new communicational processes are needed to be part of a convergence culture, consuming and producing information to create knowledge. For Jenkins [1] convergence culture arises from the relationship between three concepts: media communication convergence, participatory culture, and collective intelligence based on concepts of Lévy [2]. Thus, in the convergence culture people participate in a collective process of social interaction, sealed skills and resources association, searching for solutions to common problems, as well as producing and consuming information.

The organization of society around networks reconfigures all sectors: economic, political, social, cultural and educational [3]. The digital centers, cafe's store, spread through the city providing new spaces and opportunity towards learning, the development of socio-cultural practices, knowledge projects, social and life interventions. The schools, also placed in this context, equip themselves through private and public initiatives. By the time, whole society needs to assume the new education's challenge come from through current technology.

Inside and outside of school, children and youth are in contact with diverse technologies and media platforms, languages, and signs, often motivated by curiosity. Santaella [4] argues that in cultural backgrounds, competencies and skills of individuals are involved to participate in communication and interaction processes with the world through technology and media.

Thus, to be able to interact with the world across technology and media platforms is recognized worldwide as Media Literacy. Currently, many researchers have called Literacies, New Media Literacy, and Digital Literacy because it involves reading and writing into new types of literacy practices. For Reilly [5] the new media literacies 'can be understood as offering ways of thinking (mindsets - for example, collective intelligence) and ways of doing (skillsets - for example, transmedia navigation that recruit the traditional literacies of reading and writing) into new kinds of literacy practices' (p.8).

In this sense, considering the traditional and new social practices of reading and writing, we wonder if there are learning benefits and / or social changes that Media Literacy can provide, specifically related with youth aged from 16 to 20 who are students in high school or in the first years of college.

Our subject of research is Media Literacy and this paper aims to contribute to the debate on Media Literacy in formal education, calling attention to students' learning when some skills are linked with technologies' and media's potentials. Accordingly, with a collaborative research methodology, our proposal is to encourage Transmedia as a complementary and participatory activity, creating a multimodality experience by seeking and following stories and information across multiple media platforms in the students' learning process, both 
when they are inside and outside of school, as one of forms to reflect and to obtain answers for our research question.

For Herr-Stephenson et al. [6], 'Transmedia, by itself, means across media and describes any combination of relationships that might exist between the various texts (analog or digital) that constitute a contemporary entertainment media experience' (p.1).

Thus, it is necessary to pay attention that children and youth are growing up using technologies and medias. Schools should actively participate in such formative process for technology and media, because it will happen anyway, with or without the participation them. Related quality it would be better if formal education could involve that formative process.

\section{Media Literacy: a Field To Be Explored and Integrated in Formal Education}

Media Literacy has become a field of interest for many researchers, teachers, and stakeholders in media interaction and cognition in various countries. The United States, Canada and England and some Nordic countries have acted with greater representation in international science for the time that they have been exploring the field, still considered new. Recently, Media Literacy has been the agenda of discussion in many other countries by researchers, government, and / or associations, increasing the number of stakeholders in the field. This has contributed in composing a broader scientific scene about Media Literacy with wide spread dissemination of educational experiences.

Even with increased interest in the field, the action scope of Media Literacy is one of doubt and inquiry by stakeholders, especially teachers and education professionals. This is explained because Media Literacy is a pluralistic and interdisciplinary field involving cognition, education, communication, technology, culture, ethics, behavior, citizenship, etc.

Although there are many definitions of what is Media Literacy, it is possible to identify some skills and competencies that are in consensus among scholars and associations in the field as being able to access, to communicate, have a critical vision about the media and its contents, including analyzing, reflecting, and evaluating, as well as to have a participatory approach, acting on and with media, producing content individually and collectively.

Livingstone [7; 8] suggests that Media Literacy skills involve access, analysis, evaluation, and content creation. The author mentions the importance of the individual not only to be a media consumer, but also to be a citizen as a critical participant on communication process. Hobbs [9] highlights five essential competences of Digital and Media Literacy 'work together in a spiral of empowerment, supporting people's active participation in lifelong learning through the process of both consumption and create messages' (p.18). These are: access, analyze \& evaluate, create, reflect and act.

The national organization Partnership for 21st Century Skills [10] recommends the 4 Cs that are necessaries to work with Media Literacy: Collaboration, Communication, Critical Thinking, Creativity. For the National Association for Media Literacy Education [11], the propose of Media Literacy Education is 'to help individuals of all ages develop the habits of inquiry and skills of expression that they need to be critical thinkers, effective communicators and active citizens in today's world' (p.1).

Jenkins et al. [12] identified 11 core social skills and cultural competencies that young people should acquire if they are to be full, active, creative, and ethical participants, in this, emerging participatory culture. They are:

'Play — the capacity to experiment with your surroundings as a form of problem-solving; Performance — the ability to adopt alternative identities for the purpose of improvisation and discovery; Simulation - the ability to interpret and construct dynamic models of real world processes; Appropriation - the ability to meaningfully sample and remix media content; Multitasking — the ability to scan one's environment and shift focus as needed to salient details; Distributed Cognition - the ability to interact meaningfully with tools that expand mental capacities; Collective Intelligence - the ability to pool knowledge and compare notes with others toward a common goal; Judgment - the ability to evaluate the reliability and credibility of different information sources; Transmedia Navigation - the ability to follow the flow of stories and information across multiple modalities; Networking - the ability to search for, synthesize, and disseminate information; Negotiation - the ability to travel across diverse communities, discerning and respecting multiple perspectives, and grasping and following alternative norms' (p. 56).

Reilly [5] included one more skill 'Visualization the ability to interpret and create data representations for the purposes of expressing ideas, finding patterns and identifying trends' (p. 4). This skill was included in the original list by Massachusetts Institute of Technology, in New Media Literacy project and, now, it's in Annenberg Innovation Lab, University of Southern of California.

On the other hand some studies [13; 14] have shown that to use multiple media and technologies inside and outside school have injured student learning and performance. An example is the Multitask ability. Many students have lost attention focus when doing two or more activities at the same 
time - as, for example: participating in class, taking notes and sending SMS or listening to music, chatting with friends via Internet and studying. We have observed, regarding some young people, the same about the Judgment, Networking, Negotiation, Appropriation, and Collective Intelligence because these skills are been developed just superficially.

In reference to Brazil, the discussion of some of these problems could be seen in the recent protests to the increased bus fare in Natal, São Paulo, Rio de Janeiro, and then in other cities, resurfaced the list of grievances from population. Problems related to the poor quality of public services, corruption in government, lack of punishment for political crimes, allocation of public monies for the realization of sportive events as the Confederation Cup, the World Cup and the Olympics, considering that the country needs effective and high financial investments in both education and the public health systems.

The social movement called Passe Livre (Free Pass) spread through streets, the internet, local and international TV channels, news papers, profiles in social media, etc. The Brazilian population, mostly composed of young people, united for a better country, they compared the campaign promises with effective actions of elected politicians, and they shared their views and defended their ideals, resulting in an immeasurable amount of information to be accessed, whether in analog and digital media.

Motivated by engagement to participate actively to be part of reality, the population expressed their opinion and points of view, resulting in much information that was created, liked, shared and also manipulated. Thus, much information was adopted as truths without any extra care to check the source, authors and what was the purpose behind the message.

For Freire [15] to engage with the reality must be a participatory act, in reflection and action - praxis. The author explains 'the praxis is the reflection and action upon the world in order to transform it' (p.38).

A lot of manipulation strategies are used to change people's consciousness to believe a reality that is not real. As manipulative tools are used, images are edited in software, phrases are created to seem said by people, who in fact, never said them, videos are fragmented and taken out of context from the original with the purpose to create a new opportunistic message, myths and heroes who are adopted and widespread as saviors of the nation only to favor the interests of some.

Creativity was undoubtedly one of the strengths of that mediatized episode. Children, youth and adults created and illustrated phrases with and without humor to express their opinions and ideologies in several forms. It is undeniable that many young people have the ability to know how to use media and technology to interact with the world, but it is inadequate and has little value in of itself if they do not understand the other opportunities they can open in the interactional world afforded by connectivity and mobility. For example, they could use media and technology to change their social condition.

In summary, the episode Passe Livre showed the importance and necessity of Media Literacy in the current day as a formative and educational process to children, youth and adults. They are not reaching on a qualitative potential afforded by basic or full level of Media Literacy through developing skills and competencies needed in a hybrid culture, physical and virtual culture.

We are facing more challenges because Media Literacy initiatives in Brazil, especially public policy, have focused on access and use of technology and media in education, with emphasis in classroom contexts as for example, the online course, Media in Education, offered to teachers who are teaching at public schools.

Regarding media critical reading and thinking, in Brazil the field of Media Education has gained attention, however public policies for teacher training are almost absent when Media Education is linked with curriculum. Because of that, Media Education has been seen just as a pedagogical resource and not integrated with other knowledge fields [16].

In Brazil, as well as in many countries, Media Literacy integrated into formal education, curriculum and teacher training, is a demand from society, but is still only a government promise.

A more interactional and participatory teaching and learning process that promotes media literacy with qualitative effects in students learning and their social life will not happen suddenly. It depends on initiatives in public policy by governments, situational analysis, established principles, action plans, strategy development, and the involvement of educational professionals and the community to nurture a critical-citizen interaction with technologies and media. According to Kellner \& Share [17] 'a major challenge results from fact that Media Literacy is not a pedagogy with established principles and ready teaching procedures. Media Literacy requires: a democratic pedagogy, which involves teachers sharing power with students as they join together in the process of unveiling myths, challenging hegemony, and searching for methods of producing their own alternative media' (p.11).

One of the reasons for this difficulty is the history of education in Brazil. Formal education has its rituals that are traditional as the transmission of knowledge from teacher to students, many times isolating school from the world around it. We have made good progress toward the participatory learning process where students and teachers learn together through the dialogical relationship. Based 
on Freire's words [18] teacher is one who supports students in building their own knowledge.

Some authors not only pay attention to continuous learning but also evidence the distance between media and technology usage by children and young people when they are inside and outside school. Reilly [5] explained that 'outside their classrooms, which largely still follow a top down model of teachers dispensing knowledge, today's children learn by searching and gathering clusters of information as they move seamlessly between their physical and virtual spaces. Knowledge is acquired through multiple new tools and processes as kids accrue information that is visual, aural, musical, interactive, abstract, and concrete and then remix it into their own store house of knowledge' (p.9).

Demo [19] argues that the expectation deeper into the digital age is that of 'lifelong learning (everytime and everywhere) as a right for everyone to learn at any place and time, blending virtual and physical presence' (p.1). In the same direction, Santaella [20] explores the ubiquitous learning by allowing a kind of open learning that can be obtained in any circumstances mediated by mobile devices. The author emphasizes that the ubiquitous learning is a complementary to other types of learning since all have their limitations.

Santaella states 'what emerges is, therefore, a new learning process without teaching' (p.26). However, the ubiquitous learning seeks in other learning ways, including formal education, what is lacking in itself. The author concludes that the ubiquitous learning defies formal education to look for integration strategies, not substitution types of learning.

Teachers and students should attend to and take advantage of learning opportunities that open up when educational process is extended beyond the school space. In this sense, adopting a theoretical and practical approach to integrate formal education with socio-cultural practices from 21st century, we link Transmedia as a bridge to favor Media Literacy and can be a starting point to develop ubiquitous learning.

\section{Would Transmedia be a Bridge to Favor Media Literacy?}

The term Transmedia has been used in scientific literature with 3 complementary words: Transmedia Storytelling, Transmedia Navigation and Transmedia Play. Although the definition of each term brings elements and some different characteristics, the main concept of Transmedia remains to be in all three as [6] 'a story across multiple media platforms, with each platform making a unique and original contribution to the experience as a whole' (p. 6).

In this paper we just use the word Transmedia because we are suggesting 3 main approaches in learning and teaching practices. Accordingly, to encourage Transmedia in formal learning seems to us not only a simple and affordable way to create opportunities for students to build new knowledge on cognitive and social contexts and, promoting Media Literacy in Brazilian schools and colleges but also Transmedia can be a possible starting point to integrate formal learning and ubiquitous learning, when students are interacting within physical and virtual worlds across technologies and media with teacher guidance.

According to Jenkins [1], in an era of convergence, people become hunters and gatherers, pulling together information from multiple sources to form a new synthesis. The author adds that Transmedia 'refers to a new aesthetic that emerged in response to media convergence - an aesthetic that makes new demands on consumers and depends on the active participation of communities of knowledge' (p.49).

Aesthetic is a universe to be explored. That is, for that participation to happen, individuals must assume the role of hunters, following the flow and pieces of this universe through different media, comparing and sharing discoveries and collections through online tools, with other individuals to reach new findings, making this interactional experience concerning the knowledge object more engaging and rich.

For Vygotsky [21], the human being is constituted as itself in social interaction with others. It is through symbolic systems provided by culture that the individual will portray reality.

On this way, by Transmedia, we suggest a bridge between media interaction, culture and cognition, not only when students are interacting with multimodality but also when other skills are added and worked on in the learning process linked with the universe that intends to explore, such as problemsolving, creating common goals, remixing media content, checking information credibility, spreading content, negotiating, respecting points of view, and others.

What we are suggesting that teachers work on issues in a multimodality experience, highlighting the interactional spaces and students' autonomy when they are exploring the theme, coming from the academic curriculum or the demands that come from society.

To start Transmedia, for example, teachers can adopt a theme or a narrative from a book, film or documentary and then they should set points that extend that content to be explored across other media platforms. It is important to understand that each platform should bring a new contribution to the content, complementing and enriching it.

Another way to start Transmedia which can also be adopted by teachers is first of all to define the theme that will be explored, then to investigate what students already know about the theme and how they learned it and by which platform. After that, teachers 
should choose a film, book, photograph, etc. to be explored by students, then define points that will extend the theme and which platform will be used.

With this data, teachers know which media platform students have greater access and which ones they use outside of school. It helps teachers to design the Transmedia ways that students will explore. In the other words, experience becomes multimodality and Transmedia when the theme is explored across different media platforms in different languages.

If the narrative or theme has more elements such as, links to encourage exploration by students, there is great potential for educational opportunities, as well as more opportunities to favor Media Literacy when students are inside and outside of school. Reilly argues that digital interactions produce more knowledge and are also more influential to the learning environment in a substantial way, boosting cognition development [5].

We highlight that to use Transmedia is not only to explore how the theme is being treated in several media or what languages are used by them, but also, and mainly, the goal is to encourage students to follow the theme in several media, seeking new information that will bring a new contribution to the theme. Thus, making it more engaging and providing participation with the content even when students are or not in school.

Bautista (as cited in Pratten) establishes the classification of the media platforms in a Transmedia, through two ways of participation and two ways of experience: passive participation and active participation, individual experience and social experience [22].

With this classification, the decision to choose media more carefully and more consciously because teachers relate it to the target audience and the skills and competencies that will be involved on theme exploration to promote and to favor Media Literacy.

However, it is important that teachers know the characteristics and potential of each media to guide students on the theme exploration process, paying close attention to the participatory way that it will be expected to be explored from students.

Transmedia experience can be recorded by an involvement and interactional map. Teachers analyze through the exploration path by students to achieve some common objects, at the same time teachers should observe the skills and competences related to Media Literacy that has been built and effects in student's learning.

\section{Conclusion}

Transmedia has been used successfully by the entertainment industry, especially related to the Transmedia Storytelling. Although Transmedia in learning and teaching practices is increasing, the educational use of Transmedia is still not much.
Transmedia's potential in the learning process has been explored by researchers to build a scientific material with theoretical and practical approaches to be used by teachers and education professionals.

To use Transmedia in favor of Media Literacy was suggested by us because we believe in pedagogical potential in its structure, as well as we identify that many sociocultural practices can be stimulated to build skills and competences and to favor Media Literacy when students are in contacting with media and technology platforms.

Transmedia gives the opportunity for a dynamic, interactional and participatory learning environment when students are invited to explore the curricular content and society demands, using several languages and many media platforms.

\section{References}

[1] Jenkins, H. (2009). Cultura da Convergência (2nd ed.). Rio de Janeiro, Brazil: Aleph.

[2] Lévy, P. (1998) A Inteligencia Coletiva: Por Uma Antropologia Do Ciberespaço. São Paulo, Brazil: Loyola.

[3] Castells, M. (1999). A sociedade em rede. A era da informação: economia, sociedade e cultura (6th ed.). São Paulo, Brazil: Paz e Terra.

[4] Santaella, L. (2003). Da cultura das mídias à cibercultura: o advento do pós-humano. Revista Famecos, 22(1), 23-32.

[5] Reilly, E. (2009). "What is Learning in a Participatory Culture". Threshold. [co-editor of Spring 2009 issue].

[6] Herr-Stephenson, B., Alper, M., Reilly, E. \& Jenkins, H. (2013). $\mathrm{T}$ is for transmedia: Learning through transmedia play. Los Angeles and New York: USC Annenberg Innovation Lab and The Joan Ganz Cooney Center at Sesame Workshop. Retrieved from http://www.annenberglab.com/viewresearch/46

[7] Livingstone, S. (2004). Media literacy and the challenge of new information and communication technologies, 7 (1), pp. 3-14. London, England: LSE Research Online. Retrieved from http://eprints.lse.ac.uk/1017/1/MEDIALITERACY.pdf .

[8] Livingstone, S. (2001). Internet literacy: a negociação dos jovens com as novas oportunidades on-line. Revista Matrizes. 4 (2), 11-42.

[9] Hobbs, R. (2010). "Digital and Media Literacy: A Plan of Action". Washington, D.C.: The Aspen Institute. Retrieved from http://www.knightcomm.org/

[10] Partnership for 21st Century Skills (2011, March). Framework for 21 st Century Learning. Retrieved from http://p21.org/.

[11] National Association for Media Literacy Education (2007, November). Core principles of media literacy 
education in the United States. Retrieved from http://namle.net/wp-

content/uploads/2013/01/CorePrinciples.pdf.

[12] Jenkins, H., Clinton, K., Purushotma, R., Robinson, A. J., \& Weigel, M. (2006). Confronting the challenges of participatory culture: Media education for the 21 st century. The John D. and Catherine T. (Ed). MacArthur Foundation.

[13] Junco, R. \& Cotten, S. R., A Decade of Distraction? How Multitasking Affects Student Outcomes (September 13, 2011). Available at SSRN: http://dx.doi.org/10.2139/ssrn.1927049

[14] Ophir, E., Nass, C. I., \& Wagner, A. D. (2009). Cognitive control in media multitaskers. Proceedings of the National Academy of Sciences, 106, 15583-15587. doi:10.1073/pnas.0903620106

[15] Freire, P. (1987). Pedagogia do oprimido (17th ed.). Rio de Janeiro, Brazil: Editora Paz e Terra.

[16] Fantin, M. (2012). Mídia-Educação no currículo e na formação inicial de professores. In Fantin, M. \& Rivoltella,

[17] Kellner, D. \& Share, J. (2009). Critical media education and radical democracy. In Michael Apple, M. W., Wayne Au, and Gandin, L. A. (Ed). The Routledge International Handbook of Critical Education (pp. 281295). New York: Routledge.

[18] Freire, P. (1996). Pedagogia da autonomia: saberes necessaries à prática educativa. Rio de Janeiro, Brazil: Editora Paz e Terra.

[19] Demo, P. (2008, August 21st). TICs e Educação. Message posted to http://pedrodemo.blogspot.com/2008/08/tics-eeducacao.html

[20] Santaella, L. (2013). Desafios da ubiquidade para a educação. Revista Ensino Superior Unicamp, 9, 19-28.

[21] Vygotsky, L. S. (1998). A formação social da mente: o desenvolvimento dos processos superiores (6th ed.). São Paulo, Brazil: Martins Fontes.

[22] Pratten, R. (Ed.). (2011). Getting started in transmedia stotytelling: a practical guide for beginners.

\section{Acknowledgements}

We thank the Capes Foundation, an agency under the Ministry of Education of Brazil, The Graduate Program in Education of UFRN, and the Annenberg Innovation Lab for the opportunity to conduct part of this research at University of Southern California. 